\title{
Profit Maximization In The National Football League
}

John P. Brunkhorst, Colorado College, USA

Aju J. Fenn, Colorado College, USA

\begin{abstract}
This paper investigates if NFL teams maximize profits with respect to ticket price. We modify Ferguson et al's (1991) NHL paper as it pertains to the NFL. A profit function incorporating variable revenue and cost factors such as gate receipts and player expenses is employed. A systems model is used as the estimation procedure to identify the determinants of ticket prices for NFL franchises. The model implies a Kuhn-Tucker based cross equation parameter restriction that result from attendance capacity constraints. Results from the regression are then used in conjunction with other data to numerically test the first order necessary profit maximization conditions. The results indicate that over $80 \%$ of NFL teams set ticket prices in a manner consistent with gate receipt and profit maximization.
\end{abstract}

Keywords: National Football League, Profit Maximization, Ticket Price Determination

\section{INTRODUCTION}

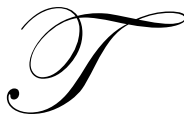

he theory of profit maximization has been a key economic concept for almost a century, Knight (1921). Profit maximization occurs when firms adjust either the quantity or price of the goods they produce in order to maximize the gap between revenues and costs. Professional sporting contests have been one of the most significant branches of the entertainment industry. Szymanski (2003) reports that in 1997 the U.S. Census Bureau found $41 \%$ of the population, roughly 110 million people, attended a spectator sporting event each year. He also states that Kagan Media estimated the annual household television viewing of sports events to be 77 billion hours per year.

According to Scully (1995) the National Football League (NFL) is an economic enterprise where every single team in the league is consistently profitable. Zimbalist (2003) states that individual owner's economic objectives differ due to the unique way each owner defines profit maximization. Some owners focus simply on money, while others believe the best way to maximize profits is to maximize the number of wins. Even though research conducted by Forbes shows that each team in the NFL makes a significant profit, it does not mean that each team maximizes potential profits. ${ }^{i}$ Constant sellouts and scalpers selling tickets above face value point to the fact that NFL franchises could raise ticket prices in order to increase profits. Perhaps some owners are more interested in winning championships than making the most money. As long as franchises are not losing money, their ultimate goal could be the glory and prestige accompanying a Super Bowl victory. On the other hand, constantly increasing ticket prices and television blackouts in local areas during non-sellout games all point to profit maximization as the main objective. These conflicting empirical findings and stylized facts prompt the question: Do NFL franchises conform to the practices of profit maximization? This paper will strive to answer that question.

The purpose of this study is to determine whether NFL franchises set ticket prices in a manner consistent with the first order necessary profit maximizing conditions. The first section will provide a review of the pertinent empirical literature on profit maximization. The second section will outline the modifications to the methodology employed by Ferguson et al. (1991) and will develop empirical models for the maximization of gate receipts with respect to ticket prices. Section three addresses the profit maximizing necessary conditions and presents the numerical equations used to test whether these conditions hold. The fourth section will present the data and regression model. The fifth section discusses the results for both the empirical model and the numerical testing of 
profit maximization. Finally, the implications of the results are presented in the concluding section.

\section{CURRENT RESEARCH ON PROFIT MAXIMIZATION}

While the theory of profit maximization has been around since the beginning of the $20^{\text {th }}$ century there have been relatively few studies that adapt this theory to professional sports leagues. Several studies have focused on the economic design of these leagues and the relationship between variables affecting the business side of professional sports.

There is a copious literature that covers studies on attendance, revenue, competitive balance, etc. Brook (2006) provides an excellent summary of the literature on profit maximizing models and inelastic ticket pricing. ElHodiri \& Quirk (1971, 1974, and 1975) present the first model of a sports league. Like us they focus on gate receipts alone. Additional work by Heilmann \& Wendling (1976) extended the El-Hodiri and Quirk effort to include additional revenue streams. Marburger (1997) has modeled sports teams as multi-product monopolists that sell both admission and concessions. Another vein of the literature examines the connection between ticket pricing and home field advantage. The reader is directed to Brook (2006) for a review of these studies.

None of the above studies account for the fact that attendance constraints in the NFL are often binding. In 2006 the NFL set a record with every game for every team selling out through the eleventh week of the season. Studies on game day attendance like the one by Welki and Zlatoper (1994) fail to account for the impact of such a constraint in their empirical specifications. However, a study by Ferguson et al. (1991) examines if NHL teams maximized profits with respect to ticket prices given a seating constraint.

Ferguson et al. (1991) investigate the issue of profit maximization in the National Hockey League (NHL) by looking at the ticket pricing behavior of teams given a stadium capacity constraint. Their study asserts that pricing differences between various packages of seating support the idea that owners use sophisticated practices to earn profits. They assume that each team considers the fan's willingness to pay for attendance. The team then maximizes profits by setting seat prices accordingly to maximize its gate receipts. Each team will have a different method for price setting due to unique franchise characteristics. The econometric results, which use Kuhn-Tucker conditions through cross equation restrictions, offer considerable support for the notion that NHL teams do follow a profit maximizing procedure in setting ticket prices.

The present study modifies the model proposed by Ferguson et al. (1991) to examine profit maximization as it applies to ticket pricing in the NFL. To the best of our knowledge no economic studies conducted on profit or revenue maximization pertaining to the NFL subject to seating capacity constraints exist. This study tests the necessary (first order) conditions of profit maximization to see if in the presence of a capacity constraint firms maximize gate receipts with respect to ticket prices. The following section outlines the mathematical models derived for both profit and ticket prices which will serve as the foundation for testing profit maximization in the NFL.

\section{PROFIT MAXIMIZATION: DERIVATION}

If owners maximize profits, they must pay close attention to the revenues generated and costs incurred throughout the season. The revenue that a team receives accrues in two main forms. The majority of revenue is collected from the gate receipts of each game. Additional revenues arise from the teams' share of NFL broadcasts and merchandise sales. Even though revenue sharing from NFL broadcasts and merchandise does make up a fairly significant part of a team's total revenue, it is approximately a fixed amount from team to team. The NFL signs contracts with national and local broadcasting agencies, Szymanski (2003). The NFL allots a share of the revenue produced from sales of NFL merchandise to be distributed among teams in the league. The revenues generated by these contracts are divided equally among all teams. The teams have virtually no control over the revenue they receive from league sharing. Therefore, owners focus on gate receipts, which they can control. Owners can set ticket prices to maximize profits for the season. 
In keeping with Ferguson et al (1991), it is assumed that the costs varying with attendance at each individual game are so small that operating costs and stadium costs should not play a large role in profit maximization. The majority of costs for each team stem from factors such as players salaries. This implies that the owners' sole objective is to maximize the difference between total gate receipts in each year and total player expenses. To do this owners will adjust ticket prices until they find a price that returns maximum profit, $\pi$, given the amount spent on players. The revenue generated by gate receipts is simply ticket price, $p$, multiplied by attendance, A. Equation (1) gives the profit maximization rule for NFL owners.

$\operatorname{Max} \pi=p * A-E$ subject to $A \leq C$

$E$ represents total player expenses. The maximum number of people that can attend any game is limited to the seating capacity, $C$, of the stadium.

Ticket price itself is a function of other variables. In keeping with Ferguson et al (1991), this study will define ticket price as a function of attendance and a vector of other variables. However, it will also incorporate player expenses as a determinant of ticket price. Equation (2) gives the ticket price function.

$p^{x}=f(A, E, z ; \theta)$

$\mathrm{P}^{x}$ is ticket price raised to the power $x, z$ is the vector of exogenous attributes of the team, and $\theta$ is the vector parameters. It is believed that both attendance and player expenses are endogenous variables. Instrumental variables will be used to handle this endogeneity to ensure that the estimates are unbiased and consistent. The instrumental variables will produce theoretical values for attendance and player expenses, which will be called $\hat{A}$ and $\hat{E}$ respectively. Therefore, the inverse demand function from equation (2) is represented by equation (3).

$p^{x}=\beta_{0}+\beta_{1} A+\beta_{2} E+\beta_{k} z$

Combining equations (1), (2) and (3) yields the profit function presented in equation (4). Since profit maximization corresponds to revenue minus costs, equation (4) will be the basis for testing empirical hypotheses regarding profit maximization.

$$
\Pi=A^{*}\left(\beta_{0}+\beta_{1}+\beta_{2} E+\beta_{k} z\right)^{(1-x)}-E
$$

\section{PROFIT MAXIMIZATION: TESTING METHODOLOGY}

A first order necessary condition for profit maximization is that the first order derivative with respect to the choice variable equals zero. Equation (5) states that, the derivative of profit function with respect to attendance equals zero.

$$
\frac{\partial \pi}{\partial A}=\frac{A^{*} \beta_{1}}{x} * P^{1-x}+P=0
$$

The second order condition states that the second derivative must be negative with respect to the choice variable attendance $A$. The derivative of $\partial \pi / \partial A$ must be taken with respect to attendance. The resulting expression is given by Equation (6).

$$
\frac{\partial \pi^{2}}{\partial A^{2}}=\frac{2 \beta_{1}}{x} * P^{1-x}+\frac{A \beta_{1}^{2}(1-x)}{x^{2}} * P^{1-2 x}
$$


As noted previously, stadium capacity places a restriction on the number of people attending a game. This constraint must be taken into account. To do this a univariate Kuhn-Tucker approach is used. A maximum profit must be generated between zero and stadium capacity. Therefore at the profit maximizing attendance, the following Kuhn-Tucker conditions must hold.

$$
\frac{\partial \pi}{\partial A} \geq 0 ; C-A \geq 0 ; \frac{\partial \pi}{\partial A} \times(C-A)=0
$$

These conditions imply the capacity constraint is binding unless local concavity exists. This study uses the third condition in (7) to represent the restriction on owners' choices because it is able to represent both the first and second conditions simultaneously. Thus the restriction equation is given by equation (8).

$$
\frac{\partial \pi}{\partial A} \times(C-A)=\left[\frac{A^{*} \beta_{1}}{x} * P^{1-x}+P\right] \times(C-A)=0
$$

Ferguson et al. (1991) use a similar restriction approach in their paper. The effects of the theoretical determinants on ticket prices in the NFL will be determined empirically by estimating the following system of equations (9) and (10) that are the empirical versions of equations (3) and (8):

$$
\begin{aligned}
& p_{i}=\beta_{0}+\beta_{1} \hat{A}_{i}+\beta_{2} \hat{E}_{i}+\beta_{k} z_{i}+\varepsilon_{1 i} \\
& {\left[\frac{A^{*} \beta_{1}}{x} * P^{1-x}+P\right] \times(C-\hat{A})=\varepsilon_{2 i}}
\end{aligned}
$$

In equations (9) and (10) $i$ represents the observation and $\varepsilon_{1 i}$ and $\varepsilon_{2 i}$ are unobservable errors terms. Using the coefficients and determinants from these equations the first and second order derivatives can be numerically calculated and evaluated for both sellout and non-sellout teams. The results of these calculations should shed some light on the maintained hypothesis of profit maximization, in the context of this paper, by NFL owners.

\section{DATA AND METHODS}

The dataset is comprised of all 32 NFL football teams over three regular seasons from 2003 to 2005. The unit of observation is a single regular season for each team. The left hand side dependent variable in this model is the average ticket price by team for each season. ${ }^{\text {ii }}$ Average ticket price was defined as a weighted average of season ticket prices for general and club-level seats for each team during a given season. The weights used were the proportion of seats in each pricing category. Ticket prices were then adjusted to 2003 dollars using the Consumer Price Index. The explanatory variables are summarized in equation (11) and briefly defined in Table 1.

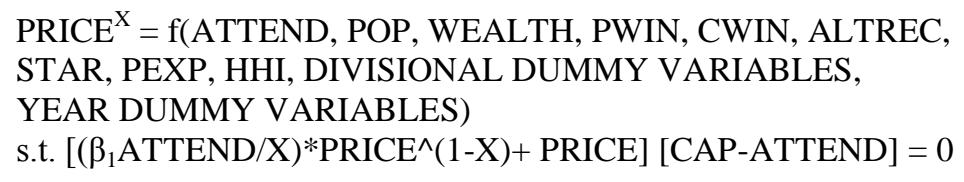

The definitions of the variables presented in the above model are displayed in Table 1. 
Table 1: Variable Definitions

\begin{tabular}{cl}
\hline Variable & \multicolumn{1}{c}{ Definition } \\
\hline X & Exponent value that PRICE was raised by \\
PRICE & Average game ticket price for season in 2003 dollars \\
ATTEND & Season home attendance \\
POP & Population of franchise's home city \\
WEALTH & Median income of franchise's home city in 2003 dollars \\
PWIN & End-of-year winning percentage for previous year \\
CWIN & End-of-year winning percentage \\
ALTREC & Alternative forms of local recreation available in home city \\
STAR & Number of Pro Bowl selections \\
PEXP & Total player expenses in 2003 dollars \\
HHI & Yearly HHI in the NFL \\
CAP & Stadium Capacity \\
NFCE & Dummy for division NFC East \\
NFCN & Dummy for division NFC North \\
NFCS & Dummy for division NFC South \\
NFCW & Dummy for division NFC West \\
AFCE & Dummy for division AFC East \\
AFCN & Dummy for division AFC North \\
AFCS & Dummy for division AFC South \\
YEAR03 & Dummy for 2003 season \\
YEAR04 & Dummy for 2004 season \\
\hline
\end{tabular}

Attendance is also believed to be an endogenous variable in the model, and is therefore dependent on the exogenous variables. The determinants that affect average ticket price also affect attendance. Attendance (ATTEND) is defined as the total number of spectators at an NFL team's home games for a given year. All attendance data was found at the NFL's website. ${ }^{\text {iii }}$ Lower ticket prices will allow more people to attend games through the usual income and substitution effects. Therefore, the theoretical prediction is that attendance will have a negative relationship with price.

The costs of running a professional football team are not small. Most of these costs are either operating expenses or player expenses. We assume that operating costs, such as stadium operation and general management costs, do not vary by large amounts across NFL teams. Since these costs are assumed to be fixed, and that data for them is not readily available, they are excluded from the model. However, expenses such as player and coach salaries, benefits, and bonuses do differ throughout the league. Even though there is a salary cap in the NFL, player expenses (EXP) vary significantly for each team. Like attendance, player expenses are believed to be endogenous in the model. Player expense data was collected from the NFL Team Valuations conducted by Forbes. ${ }^{\text {iv }}$ They were then adjusted to 2003 dollars using the Consumer Price Index. When teams spend more on their players and staff they should theoretically have to bring in more revenue to offset the increased cost. To accomplish this ticket prices should increase. This is why we expect average ticket price and player expenses to be positively related.

El-Hordiri (1971) says that the league typically gives exclusive rights to organize a team in a 35-75 mile geographical area around the home playing field. Particular demographics in each territory represented by a NFL team are potential determinants of NFL ticket prices and other endogenous variables. The total population (POP) of a territory should directly affect the number of fans wanting to attend home games. A larger population creates a greater demand for tickets, allowing owners to raise prices, leading to greater revenue. Population may be positively correlated with ticket prices in the NFL. Populations of the various NFL territories were collected from the US Census Bureau's 2000 census. $^{v}$

Ferguson et al. (1991) find per capita income and ticket prices to be positively correlated in the NHL, showing attending NHL games to be a normal good. We also expect wealth to have a positive correlation with ticket prices because NFL tickets should be a normal good. Median income (WEALTH) data was collected from the US Census Bureau's 2000 census and then adjusted to 2003 dollars using the Consumer Price Index. ${ }^{\text {vi }}$ 
The number of different professional sports teams in each territory (ALTREC) represents the possible substitutes for attending an NFL football game. Multiple sports teams may act as substitutes for each other. NFL football games are a source of entertainment and compete with other local entertainment for people's time and money. If this is the case the greater the number of sports teams in an area the lower the attendance of NFL games. On the other hand multiple sports teams may be evidence of complementary preferences of consumers. Cities with more sports teams may have a larger demand for sports and ceteris paribus, attendance at NFL events may be higher. A priori it is uncertain as to what type of impact the number of sports teams in an area will have on the ticket prices and revenue in the NFL. The measure of alternative forms of recreation is captured by the number of major league teams in a particular territory from the four major U.S. professional sports leagues: MLB, NBA, NHL, and the NFL.

There is a significant literature on the connection between winning and attendance. People prefer to watch winning teams because they attract attention. A winning team should have not only a consistent fan base but a growing one because current fans will continue to support their team and people who were not previously fans might now be attracted to the team. The success of an individual team should play a significant role in determining the prices charge for game day attendance. In any given year, the greater the success of a team, the more people will want to attend games. The performance of a team in the previous year will also affect attendance for the current year. If a team did well last year, people will expect another good season and eagerness to attend at the upcoming season's games will rise. In both cases, past and present, these factors increase the demand for attendance and can lead to changes in ticket prices. We will attempt to represent the success of NFL teams by using winning percentages. These annual winning percentages are calculated by dividing the number of games won by the number of games played. Both the current year's winning percentage (CWIN) and the previous year's winning percentage (PWIN) were collected for each team over all three years. ${ }^{\text {vii }}$ We expect that team winning percentage of the previous and current year will vary positively with ticket prices.

Downward and Dawson (2000) state, the profits a team achieves can start to fall if the team becomes "too" successful. If a team becomes so good that opposing teams have little chance of winning, fans will become bored and not want to attend games. The same applies for teams who are so bad they consistently lose. El-Hodiri and Quirk, (1971), state that predicable outcomes in sporting events lower attendance. In light of this it is necessary to control for the impact of competitive balance of the NFL on attendance.

Past empirical research on profit maximization has not taken competitive balance into account. This study will use the Herfindahl-Hirschman Index (HHI) specified in Larsen et al.(2006) to control for the impact of competitive balance on attendance in the NFL. The HHI is most commonly used to examine market concentration in industrial organization, but it is also applicable to competitive balance. In this study the HHI is used to measure how equally wins are distributed among teams in the NFL. The HHI measures the total number of wins in a season by an individual team in comparison to the total of number of wins throughout the entire league. In a season with a lack of competitive balance the HHI will be close to 1 . If wins are divided evenly throughout the league, then the HHI will be closer to 0 than in a league where a few teams win most of the games. The HHI is defined in equation (12).

$$
H H I=\sum_{i=1}^{t} \frac{2 W_{t}}{N G}
$$

$W_{t}$

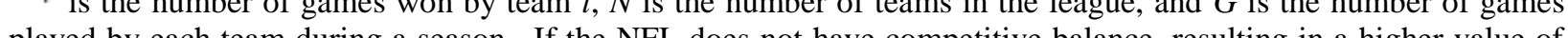
played by each team during a season. If the NFL does not have competitive balance, resulting in a higher value of HHI, then attendance at games should fall. A more equal distribution of wins should increase attendance and raise ticket prices. Therefore the maintained hypothesis is that HHI should be negatively related to ticket prices.

Berri, Schmidt, and Brook (1998) suggested an organization could shift the focus from a team's poor performance towards individual star players in order to increase attendance. We capture the star power of a team by the number of players representing the team at that year's Pro-Bowl. The NFL Pro Bowl is a yearly game played after the end of each season. Fans, players, and coaches all vote for their favorite players at each position. Players 
with the most votes are selected to represent their conference in the NFL Pro Bowl. Typically these players are regarded as the best players in the league. Therefore, it seems logical that the players voted into the Pro Bowl from an individual team (STAR) will draw fans to games to witness their exciting athletic performances. NFL teams with high star power should have higher attendance figures, allowing owners to increase ticket prices. We expect the number of Pro Bowl players on a local team to positively relate to ticket prices in a given year.

Divisional games are oftentimes of great importance to teams and fans. Historical rivalries between divisional opponents create a strong sense pride, increasing the demand for attendance. Cross section specific divisional effects are controlled for using a series of divisional dummy variables. These variables (NFCE, NFCN, NFCS, NFCW, AFCE, AFCN, AFCS) take on a value of 1 if the team being observed is part of a specific division. Otherwise it will have a value of 0 . There are eight divisions in the NFL with four in both the National Football Conference and the American Football Conference. We employ seven divisional dummy variables.

Every year brings about unforeseen changes due to external forces that could factor into the endogenous variables. An example would be hurricane Katrina causing the New Orleans Saints to play in Baton Rogue and San Antonio for the 2005 season. Time specific effects will be taken into account by using a dummy variable to represent two of the three years being observed (YEAR03, YEAR04). A value of 1 is given to any observation occurring in that year, otherwise it is 0 .

Attendance at an NFL game is unlike other goods in that there is a limit on the quantity of seats. The total number of people allowed to attend a NFL football game has a ceiling restriction placed on it. Every stadium in the NFL has a certain capacity that it theoretically cannot exceed. The total number of seats in each stadium (CAP) will therefore be used as a restriction in the model. ${ }^{\text {viii }}$ Using a capacity restraint allows the Kuhn-Tucker conditions to be enforced through the restriction equation. Ferguson et al. (1991) used the same approach in their study. However, data showed that some teams had total attendance greater than stadium capacity. If this was the case, capacity was increased so that total attendance equaled stadium capacity. With these teams now considered sell out teams, the ceiling constraint of the Kuhn-Tucker condition becomes binding. Therefore, depending on the observation, either the internal or ceiling constraint should be binding. In keeping with Ferguson et al. (1991) since capacity is only used as a restriction, its effects on ticket prices will not be measured.

\section{EMPIRICAL MODEL AND NUMERICAL TESTING: ESTIMATION AND RESULTS}

In order to incorporate both the instrumental variable and the restriction equation, a System Two-stage Least Squares (STSLS) regression approach was used to estimate the model. ATTEND was instrumented for by the variable POP. ${ }^{\mathrm{ix}}$ This primary OLS regression found the portions of the endogenous and exogenous variables that could be attributed to the instrumental variable. The fitted values produced by this regression were saved for later use.

The restriction equation on capacity of the stadium is simultaneously applied to enforce the cross equation restrictions. Therefore, the results of this regression were the coefficients that best estimated both the inverse demand model and the restriction equation.

The Arizona Cardinals were removed from the dataset to insure that the residuals were normally distributed. Removing this outlier corrected the non-normality of the error term, producing a Jarque-Bera statistic below 5.99. HHI was dropped from the model because including it as a regressor resulted in the singleton dummy problem.

Table 2 summarizes the STSLS regression results for the determinants of ticket prices in the NFL. The tstatistics are displayed in parentheses below each coefficient. A blank cell represents the omission of a variable from the model. 
Table 2: System Two-Stage Least Squared Regression Results: The Determinants of Ticket Price

\begin{tabular}{|c|c|c|c|c|}
\hline Variable & Definition & Model 1 & Model 2 & Model 3 \\
\hline $\mathrm{X}$ & Exponent value that PRICE was raised by & 1 & 1.76 & 1.8 \\
\hline $\mathrm{C}$ & & $\begin{array}{c}66.82 \\
(4.74)^{*}\end{array}$ & $\begin{array}{c}890.99 \\
(1.48)\end{array}$ & $\begin{array}{l}- \\
-\end{array}$ \\
\hline ATTEND & Season home attendance (endogenous) & $\begin{array}{c}-9.99 \mathrm{E}-05 \\
(-55.22)^{*}\end{array}$ & $\begin{array}{l}-0.0023 \\
(-2.07)^{*}\end{array}$ & $\begin{array}{l}-0.0009 \\
(-2.06)^{*}\end{array}$ \\
\hline POP & Population of franchise's home city & $\begin{array}{c}\text { IV } \\
-\end{array}$ & $\begin{array}{c}\text { IV } \\
-\end{array}$ & $\begin{array}{c}\text { IV } \\
-\end{array}$ \\
\hline WEALTH & $\begin{array}{l}\text { Median income of franchise's home city in } \\
2003 \text { dollars }\end{array}$ & $\begin{array}{c}5.81 \mathrm{E}-05 \\
(3.38)^{*}\end{array}$ & $\begin{array}{l}0.0021 \\
(5.68)^{*}\end{array}$ & $\begin{array}{l}0.0026 \\
(6.75)^{*}\end{array}$ \\
\hline PWIN & $\begin{array}{l}\text { End-of-year winning percentage for } \\
\text { previous year }\end{array}$ & $\begin{array}{c}9.49 \\
(1.64)\end{array}$ & $\begin{array}{l}364.43 \\
(3.05)^{*}\end{array}$ & $\begin{array}{l}446.04 \\
(3.39)^{*}\end{array}$ \\
\hline CWIN & End-of-year winning percentage & $\begin{array}{c}4.86 \\
(0.69)\end{array}$ & $\begin{array}{c}200.06 \\
-1.36\end{array}$ & $\begin{array}{c}229.74 \\
(1.90)\end{array}$ \\
\hline ALTREC & $\begin{array}{c}\text { Alternative forms of local recreation } \\
\text { available in home city }\end{array}$ & $\begin{array}{c}2.31 \\
(2.50)^{*}\end{array}$ & $\begin{array}{c}77.21 \\
(3.95)^{*}\end{array}$ & $\begin{array}{c}93.67 \\
(4.55)^{*}\end{array}$ \\
\hline STAR & Number of Pro Bowl selections & $\begin{array}{c}0.08 \\
(0.11)\end{array}$ & $\begin{array}{l}-0.11 \\
(-0.01)\end{array}$ & - \\
\hline PEXP & Total player expenses in 2003 dollars & $\begin{array}{c}3.54 \mathrm{E}-09 \\
(0.031)\end{array}$ & $\begin{array}{c}4.57 \mathrm{E}-07 \\
(0.19)\end{array}$ & $\begin{array}{l}- \\
-\end{array}$ \\
\hline HHI & Yearly HHI in the NFL & - & - & - \\
\hline CAP & Stadium Capacity & $\begin{array}{c}\text { restriction } \\
-\end{array}$ & $\begin{array}{c}\text { restriction } \\
-\end{array}$ & $\begin{array}{c}\text { restriction } \\
-\end{array}$ \\
\hline NFCE & Dummy for division NFC East & $\begin{array}{c}5.89 \\
(1.37)\end{array}$ & $\begin{array}{l}175.57 \\
(-1.72)\end{array}$ & $\begin{array}{l}108.40 \\
(1.31)\end{array}$ \\
\hline NFCN & Dummy for division NFC North & $\begin{array}{l}-0.65 \\
(-0.16)\end{array}$ & $\begin{array}{l}11.39 \\
(0.13)\end{array}$ & - \\
\hline NFCS & Dummy for division NFC South & $\begin{array}{l}-3.22 \\
(-0.75)\end{array}$ & $\begin{array}{l}-108.74 \\
(-1.22)\end{array}$ & $\begin{array}{l}-124.15 \\
(-1.64)\end{array}$ \\
\hline NFCW & Dummy for division NFC West & $\begin{array}{l}-5.39 \\
(-1.28)\end{array}$ & $\begin{array}{l}-176.49 \\
(-2.01)^{*}\end{array}$ & $\begin{array}{l}-188.25 \\
(-2.26)^{*}\end{array}$ \\
\hline AFCE & Dummy for division AFC East & $\begin{array}{c}4.96 \\
(1.13)\end{array}$ & $\begin{array}{l}189.05 \\
(1.84)\end{array}$ & $\begin{array}{l}149.68 \\
(1.74)\end{array}$ \\
\hline $\mathrm{AFCN}$ & Dummy for division AFC North & $\begin{array}{c}0.01 \\
(0.02)\end{array}$ & $\begin{array}{c}2.57 \\
(0.03)\end{array}$ & - \\
\hline AFCS & Dummy for division AFC South & $\begin{array}{l}-3.37 \\
(-0.82)\end{array}$ & $\begin{array}{l}-94.87 \\
(-1.11)\end{array}$ & - \\
\hline YEAR03 & Dummy for 2003 season & $\begin{array}{l}-2.83 \\
(-1.14)\end{array}$ & $\begin{array}{l}-101.25 \\
(-1.98)^{*}\end{array}$ & $\begin{array}{l}-114.56 \\
(-2.06)^{*}\end{array}$ \\
\hline YEAR04 & Dummy for 2004 season & $\begin{array}{l}-2.07 \\
(-0.86)\end{array}$ & $\begin{array}{l}-82.23 \\
(-1.66)\end{array}$ & $\begin{array}{l}-99.97 \\
(-1.79)\end{array}$ \\
\hline R-squared & & 0.28 & 0.42 & 0.48 \\
\hline
\end{tabular}

*Significant at a 5\% significance level, $(\mathrm{t}$-critical $=1.96)$

The fit of model 1 is relatively low. It explains only $28 \%$ of the variation in the dependent variable PRICE. Only ATTEND, ALTREC, and WEALTH are significant at the 5\% level. The fact that previous research by Ferguson et al. (1991) and Boyd and Boyd (2001) found similar variables to be significant questions the specification of Model 1.

In Model 2, PRICE is raised by an exponential factor of 1.76 . Model 2 explains $42 \%$ of the variation in PRICE around its mean given that only three years of data and 93 observations were used. Six independent variables were significant at the $5 \%$ significance level. 
Model 3 has the best fit of any model tested with the model explaining just below half the variation in PRICE. Even though this model had the best fit, it probably suffers from omitted variable bias. Work by Boyd and Boyd (2001) and Ferguson et al. (1991) found these omitted variables to be significant determinants of ticket prices and attendance. The significance of variables in the regression is downplayed by Ferguson et al (1991) because they claim that the testable implications of the theory are based on first and second order conditions. However, as a rule of thumb, standard errors of composite statistics (i.e. say those constructed from standard errors of regression coefficients that are significant) are more likely to be significant than those based on insignificant regression coefficients. For this reason we present the results from Model 2 for inference.

This study found attendance (ATTEND) to have a negative and statistically significant impact on ticket prices. The fact that the partial coefficient was negative is central to the theory of profit maximization. The demand for attending an NFL game is a normal good such that as ticket prices go up fewer people are willing to pay to watch the game. The fact the partial coefficient for ATTEND was significant is extremely important because it plays a major role in analyzing the first and second profit maximizing conditions. If this partial coefficient was not significant, the results of the numerical analysis would not be credible.

Estimation found PEXP to have a positive but insignificant relationship with PRICE. This positive relationship was as expected. Based on the estimation, the inclusion of PEXP in this model was not as necessary as originally thought. It's not certain why PEXP doesn't play a larger role in determining ticket price. Perhaps the fact that the NFL has a salary cap reduces the significance of player expenses.

When examining the effects different characteristics of a team's territory, the partial coefficient for WEALTH was found to be statistically significant and positively related to average ticket price. This result suggests that attending NFL games is a normal good. The other territorial variable POP was used as an instrumental variable and was therefore not estimated as a determinant of ticket prices.

The number of different professional sports teams in an NFL team's territory (ALTREC) was found to have a statistically significant and positive relationship with PRICE. Based on these results it seems that other teams in a certain territory don't compete as substitutes, but instead increase the pride fans have for teams in their territory. This research has found that ALTREC actually increases support of a NFL team because people in the territory take pride in the teams representing them. This pride increases the demand for attendance and therefore owners are able to charge higher ticket prices.

The coefficient of the winning percentages for NFL teams is positive and significant for PWIN and positive and insignificant for CWIN. These two winning percentages were used to analyze the effects of team success. The values for PWIN show the more a team wins in the previous season, the higher ticket prices will become the following year. This means prior team success does play a significant role in determining ticket prices. The insignificant result for CWIN was somewhat expected. An owner has to set ticket prices before the season begins. He doesn't know exactly how well his team will perform in the upcoming season and can only use a predicted value of success. Sometime this predicted value is inaccurate. Since the actual value of CWIN is not readily available to the owner at the time he makes his ticket pricing decision it is not surprising that CWIN does not play a significant role in determining these prices.

STAR has a negative, but insignificant relationship with ticket price. This result contradicts the expected positive relationship. However, the insignificance of this partial coefficient means the validity and accuracy are questionable.

Of the dummy variables used to represent the divisional effects in the NFL, only the partial coefficient of the NFC Western Division (NFCW) showed significance in the regression. Every other division's partial coefficient was insignificant at the 5\% significance level and was not analyzed in detail.

The other set of dummy variables used in this data set accounted for the different seasons of the NFL. The 2003 season variable (YEAR03) was significant and negatively related to ticket prices. The 2004 season's variable (YEAR04) also had a negative, yet insignificant, relationship with price. The 2005 season did not have a dummy 
variable, so it is assumed its partial coefficient value is 0 , which is greater than YEAR04. This increasing trend in the partial coefficient from year to year shows that ticket prices have risen on average in every season..

Following the regression, equations (5) and (6) were used to determine the first and second order derivatives for each observation. The values for the derivatives were calculated by plugging in the individual $A$ and $P$ values found in each observation's data set and the $\beta_{1}$ and $x$ values determined by Model 2. Table 3 shows the results of this analysis for every team in the NFL over all three seasons. These results were then checked for significance by conducting a t-statistic test. The t-statistics for the first and second-order derivatives had to be derived by hand and numerically calculated. When developing these $t$-statistics the methods outlined in Goldberger (1964) were used to calculate the standard error for each derivative. The Delta Method, outlined in Davidson and McKinnon (2004), was also used in order to approximate the standard error of a nonlinear function that occurred in the second-order derivative's t-statistic. The Delta Method incorporates Taylor's Theorem in order to produce a linear approximation of the nonlinear function, from which the standard error of the original nonlinear function can be approximated. The t-statistics are reported in parentheses below each derivative value. These t-statistics test the null hypothesis that the derivative value is not equal to zero. If the $\mathrm{t}$-statistic value is greater than the $\mathrm{t}$-critical value of 1.96 for $5 \%$ significance level, then the derivative value is significantly greater than zero.

The values reported in Table 3 were used to test the following conditions of profit maximization shown in Figure 1.

\section{Figure 1: Conditions of Profit Maximization}

First-Order Profit Maximization Condition

i) $\frac{\partial \pi}{\partial A}=0$ for non-sellout team

ii) $\frac{\partial \pi}{\partial A} \geq 0$ for sellout teams

Second-Order Profit Maximization Condition

i) $\frac{\partial \pi^{2}}{\partial A^{2}}<0$ for non-sellout teams

ii) $\frac{\partial \pi^{2}}{\partial A^{2}}$ unrestricted for sellout teams

The first-order conditions of profit maximization are very strongly supported by the estimation results provide in Table 3. Numerical evaluation showed that all sellout teams had a first derivative that was greater than or equal to zero. This means every single sellout team satisfied the first-order condition necessary for profit maximization. 11 out of 28 sellout teams had a positive first derivative that was significantly greater than zero at the $5 \%$ significance level. The other 17 sellout teams all had positive first derivatives that were not significantly different from zero.

The fact that every sellout team had a positive derivative that satisfied the profit maximization condition questions the biasness of the t-statistic test. If the t-statistic test was biased, this test of the profit maximizing conditions would not be valid. However, these suspicions are dispelled by the fact that non-sellout teams' first derivatives take on both positive and negative values. Also, some of these second derivatives fail to accept the profit maximization conditions. 
Table 3: Numerical Results for the First and Second Derivatives of the Profit Function *sellout season

\begin{tabular}{|c|c|c|c|c|c|c|c|c|c|}
\hline \multirow[b]{2}{*}{ Team } & \multicolumn{3}{|c|}{2003} & \multicolumn{3}{|c|}{2004} & \multicolumn{3}{|c|}{2005} \\
\hline & $\partial \pi / \partial A$ & & $\partial \pi^{2} / \partial A^{2}$ & $\partial \pi / \partial A$ & & $\partial \pi^{2} / \partial A^{2}$ & $\partial \pi / \partial A$ & & $\partial \pi^{2} / \partial A^{2}$ \\
\hline \multirow[t]{2}{*}{ Arizona Cardinals } & 2.61 & & -0.0001999 & 2.66 & & -0.00020 & 8.28 & & -0.0001843 \\
\hline & $(0.125)$ & & $(-0.0091)$ & $(0.128)$ & & $(-0.0091)$ & $(0.423)$ & & $(-0.0100)$ \\
\hline \multirow[t]{2}{*}{ Atlanta Falcons } & 19.46 & & -0.0001631 & 19.49 & & -0.000163 & 38.14 & & -0.000129 \\
\hline & $(1.200)$ & & $(-0.0124)$ & $(1.202)$ & & $(-0.0124)$ & $(2.815)$ & & $(-0.0173)$ \\
\hline \multirow[t]{2}{*}{ Baltimore Ravens } & 19.63 & & -0.000156 & 25.73 & & -0.0001439 & 29.22 & & -0.0001376 \\
\hline & (1.080) & & $(-0.0120)$ & (1.504) & & $(-0.0133)$ & $(1.743)$ & & $(-0.0140)$ \\
\hline \multirow{2}{*}{ Buffalo Bills } & 22.07 & & -0.000159 & 25.41 & & -0.0001513 & 26.20 & & -0.0001502 \\
\hline & $(1.435)$ & & $(-0.0131)$ & $(1.686)$ & & $(-0.0139)$ & $(1.768)$ & & $(-0.0141)$ \\
\hline \multirow[t]{2}{*}{ Carolina Panthers } & 18.11 & & -0.0001617 & 18.01 & & -0.0001618 & 20.72 & & -0.0001561 \\
\hline & (1.0336) & & $(-0.0119)$ & (1.024) & & $(-0.0118)$ & $(1.211)$ & & $(-0.0124)$ \\
\hline \multirow[t]{2}{*}{ Chicago Bears } & 12.30 & $*$ & -0.0001753 & 16.77 & $*$ & -0.0001644 & 21.60 & $*$ & -0.0001543 \\
\hline & $(0.664)$ & & $(-0.0108)$ & $(0.943)$ & & $(-0.0116)$ & $(1.274)$ & & $(-0.0126)$ \\
\hline \multirow[t]{2}{*}{ Cincinnati Bengals } & 14.87 & $*$ & -0.0001806 & 24.87 & $*$ & -0.0001557 & 32.70 & $*$ & -0.0001403 \\
\hline & $(0.947)$ & & $(-0.0116)$ & $(1.748)$ & & $(-0.0140)$ & $(2.476)$ & & $(-0.0163)$ \\
\hline Cleveland Browns & 38.12 & & -0.0001328 & -3.77 & & -0.0002271 & -2.52 & & -0.000228 \\
\hline & $(3.192)$ & & $(-0.0185)$ & $(-0.175)$ & & $(-0.0082)$ & $(-0.122)$ & & $(-0.0083)$ \\
\hline Dallas Cowboys & 20.04 & & -0.0001527 & 32.00 & & -0.0001325 & 31.98 & & -0.0001326 \\
\hline & $(1.082)$ & & $(-0.0121)$ & $(1.922)$ & & $(-0.0146)$ & $(1.920)$ & & $(-0.0146)$ \\
\hline Denver Broncos & 3.73 & & -0.0001962 & 7.65 & & -0.0001857 & 13.55 & & -0.0001711 \\
\hline & $(0.180)$ & & $(-0.0093)$ & $(0.387)$ & & $(-0.0099)$ & $(0.730)$ & & $(-0.0109)$ \\
\hline Detroit Lions & 27.87 & $*$ & -0.0001456 & 31.54 & $*$ & -0.0001391 & 40.06 & & -0.0001259 \\
\hline & $(1.855)$ & & $(-0.0144)$ & $(2.172)$ & & $(-0.0153)$ & $(2.976)$ & & $(-0.0178)$ \\
\hline Green Bay Packers & 47.76 & $*$ & -0.0001157 & 47.63 & $*$ & -0.0001148 & 66.88 & $*$ & $-9.607 \mathrm{E}-05$ \\
\hline & $(3.589)$ & & $(-0.0197)$ & $(3.563)$ & & $(-0.0196)$ & $(5.770)$ & & $(-0.0263)$ \\
\hline Houston Texans & 2.19 & $*$ & -0.0002047 & 2.34 & & -0.000212 & 23.18 & & -0.0001629 \\
\hline & $(0.108)$ & & $(-0.0091)$ & $(0.121)$ & & $(-0.0091)$ & $(1.707)$ & & $(-0.0139)$ \\
\hline Indianapolis Colts & 25.96 & & -0.0001463 & 31.85 & & -0.0001328 & 38.78 & & -0.0001232 \\
\hline & $(1.484)$ & & $(-0.0133)$ & $(1.910)$ & & $(-0.0145)$ & $(2.469)$ & & $(-0.0162)$ \\
\hline Jacksonville Jaguars & 24.80 & & -0.0001139 & 31.87 & & -0.0001324 & 38.69 & & -0.000123 \\
\hline & $(1.393)$ & & $(-0.0130)$ & (1.897) & & $(-0.0145)$ & $(2.437)$ & & $(-0.0161)$ \\
\hline Kansas City Chiefs & 32.17 & & -0.0002124 & 34.25 & & -0.0001407 & 33.49 & & -0.0001413 \\
\hline & $(2.494)$ & & $(-0.0164)$ & $(2.878)$ & & $(-0.0175)$ & $(2.730)$ & & $(-0.0170)$ \\
\hline Miami Dolphins & 32.98 & & -0.000145 & 30.30 & & -0.0001396 & 35.98 & & -0.0001305 \\
\hline & $(2.202)$ & & $(-0.0155)$ & $(1.985)$ & & $(-0.0148)$ & $(2.475)$ & & $(-0.0163)$ \\
\hline Minnesota Vikings & 23.82 & & -0.0001425 & 21.90 & & -0.000158 & 28.50 & & -0.0001448 \\
\hline & $(1.605)$ & & $(-0.0137)$ & (1.389) & & $(-0.0123)$ & $(1.924)$ & & $(-0.0146)$ \\
\hline New England Patriots & 11.25 & & -0.0001427 & 11.73 & & -0.0001857 & 20.85 & & -0.0001584 \\
\hline & $(0.655)$ & & $(-0.0107)$ & $(0.692)$ & & $(-0.0108)$ & $(1.271)$ & & $(-0.0126)$ \\
\hline New Orleans Saints & 24.79 & & -0.0001296 & 34.46 & & -0.000134 & 34.17 & & -0.0001342 \\
\hline & $(1.547)$ & & $(-0.0134)$ & $(2.417)$ & & $(-0.0161)$ & $(2.373)$ & & $(-0.0160)$ \\
\hline New York Jets & 3.61 & & -0.0001877 & 1.52 & & -0.0002115 & 4.94 & & -0.0002001 \\
\hline & $(0.189)$ & & $(-0.0093)$ & $(0.076)$ & & $(-0.0089)$ & $(0.256)$ & & $(-0.0095)$ \\
\hline NY Giants & 21.09 & $*$ & -0.000148 & 25.41 & & -0.0001493 & 29.93 & & -0.0001412 \\
\hline & $(1.291)$ & & $(-0.0126)$ & $(1.622)$ & & $(-0.0137)$ & $(2.001)$ & & $(-0.0148)$ \\
\hline Oakland Raiders & 13.61 & & -0.0001761 & 27.84 & & -0.000145 & 33.71 & & -0.000135 \\
\hline & $(0.779)$ & & $(-0.0111)$ & $(1.829)$ & & $(-0.0143)$ & $(2.337)$ & & $(-0.0158)$ \\
\hline Philadelphia Eagles & 1.17 & $*$ & -0.0002099 & 5.239901 & $*$ & -0.0001965 & 8.48 & $*$ & -0.0001867 \\
\hline & $(0.057)$ & & $(-0.0089)$ & $(0.267)$ & & $(-0.0095)$ & $(0.446)$ & & $(-0.0101)$ \\
\hline Pittsburgh Steelers & 33.03 & & -0.00013 & 29.93 & $*$ & -0.0001319 & 28.30 & $*$ & -0.0001336 \\
\hline & $(1.953)$ & & $(-0.0147)$ & $(1.623)$ & & $(-0.0137)$ & $(1.494)$ & & $(-0.0133)$ \\
\hline San Diego Chargers & 2.61 & & -0.0001999 & 2.66 & & -0.00020 & 8.28 & & -0.0001843 \\
\hline & $(0.125)$ & & $(-0.0091)$ & $(0.128)$ & & $(-0.0091)$ & $(0.423)$ & & $(-0.0100)$ \\
\hline San Francisco 49ers & 19.46 & & -0.0001631 & 19.49 & & -0.000163 & 38.14 & & -0.000129 \\
\hline & $(1.200)$ & & $(-0.0124)$ & $(1.202)$ & & $(-0.0124)$ & $(2.815)$ & & $(-0.0173)$ \\
\hline Seattle Seahawks & 19.63 & & -0.000156 & 25.73 & & -0.0001439 & 29.22 & & -0.0001376 \\
\hline & $(1.080)$ & & $(-0.0120)$ & (1.504) & & $(-0.0133)$ & (1.743) & & $(-0.0140)$ \\
\hline St. Louis Rams & 22.07 & & -0.000159 & 25.41 & & -0.0001513 & 26.20 & & -0.0001502 \\
\hline & $(1.435)$ & & $(-0.0131)$ & $(1.686)$ & & $(-0.0139)$ & $(1.768)$ & & $(-0.0141)$ \\
\hline Tampa Bay Buccaneers & 18.11 & & -0.0001617 & 18.01 & & -0.0001618 & 20.72 & & -0.0001561 \\
\hline & $(1.0336)$ & & $(-0.0119)$ & $(1.024)$ & & $(-0.0118)$ & $(1.211)$ & & $(-0.0124)$ \\
\hline Tennessee Titans & 12.30 & $*$ & -0.0001753 & 16.77 & $*$ & -0.0001644 & 21.60 & $*$ & -0.0001543 \\
\hline & $(0.664)$ & & $(-0.0108)$ & $(0.943)$ & & $(-0.0116)$ & $(1.274)$ & & $(-0.0126)$ \\
\hline Washington Redskins & 14.87 & $*$ & -0.0001806 & 24.87 & $*$ & -0.0001557 & 32.70 & $*$ & -0.0001403 \\
\hline & $(0.947)$ & & $(-0.0116)$ & $(1.748)$ & & $(-0.0140)$ & $(2.476)$ & & $(-0.0163)$ \\
\hline
\end{tabular}


Non-sellout teams tend to support the first-order profit maximization condition but with some mixed results. The first derivative should not differ significantly from zero for non-sellout teams, but in fact 17 out of the 68 non-sellout teams actually have a significantly positive first derivative at the 5\% significance level. In the other 51 non-sellout seasons the first derivative wasn't significantly different from zero, and therefore satisfied the firstorder condition. This means $75 \%$ of the non-sellout teams satisfy the first order conditions necessary for profit maximization.

Of the 96 observations tested in the NFL during the 2003 through the 2005 season 79 out of 96 teams, or $82 \%$, produce first derivatives consistent with the first-order necessary profit maximization conditions. This shows that a very high percentage of the first-order results are in accordance with the conditions outlined for the model.

The results associated with the second-order profit maximization condition produced somewhat mixed results. Numerical evaluation showed every second derivative having a negative value that was not significantly different from zero. While these values are completely acceptable for all sellout teams based on the second-order condition, they are unacceptable for non-sellout teams. Although the second derivatives are negative, their insignificance questions their credibility.

The second-order condition of profit maximization determines whether a certain price level is profit maximizing or minimizing. If the value is negative, the price level is closer to the profit maximizing position. If it is positive, the price level is closer to a profit minimizing position. Even though the second derivatives are not significantly different from zero, the fact that they all have negative values supports the theory that they are closer to a profit maximizing position. Also, given that research by Forbes found all NFL franchises to be making a positive profit, it is hard to believe that any NFL franchise would be operating at a profit minimizing position. ${ }^{\mathrm{x}}$ Therefore, this study concludes all teams are setting ticket prices at a level consistent with profit maximization, not profit minimization. Even though the second-order derivatives do not fully support this statement, other sources of information overcome the non-supportive second derivative results.

\section{CONCLUSIONS}

This study has attempted to determine if NFL franchises act in a manner consistent with profit maximizing behavior by setting ticket prices at a level corresponding to the profit maximization conditions. Adapting the methodology developed by Ferguson et al. (1991), profit maximization is tested by focusing on the gate receipts generated by ticket prices and attendance at NFL football games.

We find that results produced through numerical testing of the first and second order derivatives of our profit model offer strong support for the hypothesis that NFL franchises act in accordance with profit maximizing behavior. These findings go against the notion that franchises always try to win the most games as possible. Winning, although related to profit, is definitely not the only thing on the mind of NFL owners. This evidence suggests that behavior of professional sport franchises may reflect the same profit maximizing approach seen in other competitive market industries. Perhaps professional sports leagues display more microeconomic characteristics seen in other competitive industries than previously thought. The findings of this research provide a potential gateway towards future microeconomic research in the area of professional sports.

\section{FOOTNOTES}

1 Research by Forbes has shown that NFL franchises consistently produce positive revenues and operating incomes. They also have a debt to value ratio below 1. All of which point to NFL franchises being profit-making entities. This data can be retrieved from: http://www.forbes.com/2005/08/31/football-valuations-charts_05nfl.html

2 Average ticket price calculated by Team Marketing Report was retrieved from: http://www.teammarketing.com/fci.cfm?page=fci nfl $03 . c f m$.

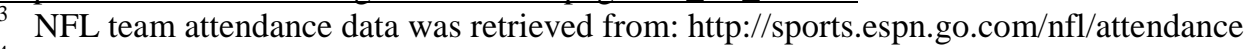

4 Player expense data was retrieved from: http://www.forbes.com/2005/08/31/football-valuationscharts_05nfl.html

5 Median income data for metropolitan statistical areas was retrieved from: http://factfinder.census.gov/servlet/DatasetMainPageServlet?_program=DEC\&_submenuId=factsheet_1\&_lang=en \& $\mathrm{ts}=$. 
6 Population data for metropolitan statistical areas was retrieved from: http://factfinder.census.gov/servlet/DatasetMainPageServlet?_program=DEC\&_submenuId=factsheet_1\&_lang=en \& ts $=$.

7 Team records recording both wins and losses were retrieved from: http://sports.espn.go.com/nfl/standings

8 Stadium capacities were retrieved from: http://www.stadiumsofnfl.com/capacity.htm.

9 PEXP was found to be insignificant when regressed against PRICE, and was therefore uncorrelated with the residuals. PEXP was used as an exogenous variable from then on and required no instrumental variable.

10 See Footnote \#1

\section{REFERENCES}

1. Berri, David J., Martin B. Schmidt, and Stacey L. Brook, Stars at the Gate: The Impact of Star Power on NBA Gate Revenues, Journal of Sports Economics, Vol. 5, No. 1, pp. 33-50, Feb. 2004.

2. Boyd, David W., and Laura A. Boyd, The Home Field Advantage: Implications for the Pricing of Tickets to Professional Team Sporting Events, The Economics of Sport, Vol. 2 pp. 254-64, 2001.

3. Evaluating Inelastic Ticket Pricing Models, Stacey L. Brook, International Journal of Sports Finance, vol 1, 2006, 140-150

4. Carlson, Sune, A Study of the Pure Theory of Production, Kelly and Millman, New York, NY, 1956.

5. Coates, Dennis, Spending on Sports: Evidence from the Consumer Expenditure Survey, Working paper, UMBC Department of Economics.

6. Davidson, Russell, and James G. MacKinnon, Econometric Theory and Methods, Oxford University Press, New York, NY, 2004.

7. Demmert, Henry G., The Economics of Professional Team Sports, Lexington Books, Lexington, MA, 1973.

8. Downward, Paul, and Alistair Dawson, The Economics of Professional Team Sports, Routledge, New York, NY, 2000.

9. Eatwell, John, Murray Milgate, Peter K. Newman, and Robert Harry Inglis Palgrave, The New Palgrave: A Dictionary of Economics, Stockton Press, New York, NY, 1987.

10. El-Hodiri, Mohamed, and James Quirk, An Economic Model of a Professional Sports League, Journal of Political Economy, Vol. 79, No. 6, pp. 1302-19, Nov.-Dec. 1971.

11. El-Hodiri, Mohamed, and James Quirk, The Economic Theory of a Professional Sports League, In R.G. Noll (Ed.), Government and the Sports Business, Vol. 79, pp. 33-80, 1974.

12. El-Hodiri, Mohamed, and James Quirk, Stadium Capacities and Attendance in Professional Sports, In S. P. Ladany (Ed.), Management Science Applications to Leisure-Time Operation, North Holland Publishing Company, Amsterdam, pp. 246-262, 1975.

13. Ferguson, D. G., The Pricing of Sports Events: Do Teams Maximize Profit?, Journal of Industrial Economics, Vol. 39, No. 3, pp. 297-310, Mar. 1991.

14. Fort, Rodney, and James Quirk, Cross-Subsidization, Incentives, and Outcomes in Professional Team Sports Leagues, Journal of Economic Literature, Vol. 33, No. 3, pp. 1265-99, Sept. 1995.

15. Fort, Rodney, and Young Hoon Lee, Fan Demand and the Uncertainty of Outcome Hypothesis, Working paper, Washington State University.

16. Fort, Rodney D., Sports Economics, Prentice Hall, Upper Saddle River, NJ, 2003.

17. Goldberger, Arthur S., Econometric Theory, John Wiley \& Sons, Inc., New York, NY, 1964.

18. Hausman, Daniel M., Capital, Profits, and Prices: An Essay in the Philosophy of Economics, Columbia University Press, New York, NY, 1981.

19. Heilmann, R. L. and W. R. Wendling, A Note on Optimum Pricing Strategies for Sports Events, In R. E. Machol, S. P. Ladany, and D. G. Morrison (Eds.), Management Science in Sports, North-Holland Publishing Company, Amsterdam, pp. 91-99, 1976.

20. Kern, William S., and W. E. Kern, The Economics of Sports, Upjohn Institute for Employment Research, Kalamazoo, MI, 2000.

21. Knight, Frank Hyneman, Risk, Uncertainty and Profit, Houghton Mifflin Company, Boston, MA, 1921.

22. Knowles, Glenn, Keith Sherony, and Mike Haupert, The Demand for Major League Baseball: A Test of the Uncertainty of Outcome Hypothesis, The Economics of Sport, Vol. 2, pp. 228-236, 2001.

23. Koplin, H. T., The Profit Maximization Assumption, Oxford Economic Papers, Vol. 15, No. 2, pp. 130139, Jul. 1963 
24. Larsen, Andrew, Aju J. Fenn, and Erin Leanne Spenner, The Impact of Free Agency and the Salary Cap on Competitive Balance in the National Football League, Journal of Sports Economics, Vol. 7, No. 4, Nov. 2006

25. Leeds, Michael A., and Peter Von Allmen, The Economics of Sports, 2nd ed, Pearson Addison Wesley, New York, NY, 2005.

26. Marburger, D., Optimal Ticket Pricing for Performance Goods, Managerial and Decision Economics, Vol. 18, pp. $375-381,1997$.

27. Nicholson, Walter, Microeconomic Theory: Basic Principles and Extensions, 3rd ed, Dryden Press, Chicago, IL, 1985.

28. Pindyck, Robert S., and Daniel L. Rubinfeld, Econometric Models and Economic Forecasts, 4th ed, Irwin McGraw-Hill, 1976.

29. Primeaux, Patrick, and John Stieber, Profit Maximization: The Ethical Mandate of Business, Austin \& Winfield, San Francisco, CA, 1995.

30. Sandy, Robert, Peter J. Sloane, and Mark S. Rosentraub, The Economics of Sport: An International Perspective, Palgrave Macmillan, New York, NY, 2004.

31. Scully, Gerald W., The Market Structure of Sports, University of Chicago Press, Chicago, Il, 1995.

32. Szymanski, Stefan, The Economic Design of Sporting Contests, Journal of Economic Literature, Vol. 41, No. 4, 137-87, Dec. 2003.

33. Von Mises, Ludwig, Profit and Loss, Consumers-Producers Economic Service, South Holland, Il, 1951.

34. Welki, A. M. and T. J. Zlatoper, US Professional Football: The Demand for Game-Day Attendance in 1991, Managerial and Decision Economics, Vol. 15, pp. 489-495, 1994.

35. Zimbalist, Andrew, Sport as Business, Oxford Review of Economic Policy, Vol. 19, No. 4, pp. 503-11, 2003. 